\title{
Dominance of natural aerosols over India in pre-monsoon: inferences from the lockdown effects
}

\author{
S. S. Prijith*, J. Srinivasulu and M. V. R. Sesha Sai \\ National Remote Sensing Centre, Indian Space Research Organisation, Hyderabad 500 037, India
}

Changes in absorbing and composite aerosols over India during the first phase of lockdown are examined, using multi-satellite observations. While MODIS shows $-16.17 \pm 1.35 \%$ reduction in AOD over the Indian landmass, OMI shows a decrease of $-22.4 \pm$ $1.36 \%(-26.2 \pm 1.17 \%)$ in AOD (AAOD). Considerable fraction of this AOD difference is contributed by the changes in aerosols at higher altitudes. While reduction in AOD of $-38.05 \pm 1.06 \%(-39.4 \pm 1.12),-23.02 \pm$ $2.63 \%(-17.08 \pm 2.12)$ and $-18.98 \pm 2.86 \%(-28.38 \pm$ $2.39 \%$ ) is observed over IGP, Northwest and Southern Peninsula respectively from MODIS (OMI), enhancement in AOD of $5.16 \pm 2.44 \%(6.82 \pm 2.86 \%)$ is seen over Centralwest India. Reduction in absorbing aerosols over IGP is $-\mathbf{3 9 . 1 8} \pm \mathbf{1 . 2 5 \%}$, whereas that over Southern Peninsula is $-\mathbf{3 3 . 1} \pm \mathbf{2 . 0 3} \%$. These changes are significantly contributed by the changes in dust aerosols, in addition to the decrease in anthropogenic aerosols. Though there is a reduction in aerosol loading, compared to previous years, gradual increase in AOD and AAOD is seen even during the lockdown period due to strengthening of dust transport. Moreover, the reduction in total (absorbing) aerosol loading over India during the lockdown phase is only $20 \%$ $\mathbf{2 6 \%}$, with significant contribution from higher altitudes, even in the absence of major anthropogenic sources. These results show the dominance of natural aerosols over India during pre-monsoon.

Keywords: Absorbing aerosols, anthropogenic aerosols, COVID-19, dust, forest fire, lockdown, natural aerosols.

\section{Introduction}

ATMOSPHERIC aerosol is recognized as a major climate forcing agent ${ }^{1-3}$, due to its potential to alter the earth's energy balance through direct interactions with radiation $^{4-6}$ and also through modifying cloud properties ${ }^{7}$. Even after the active research in this area for decades, the level of scientific understanding on the climate impacts of aerosols, through the modifications of cloud properties, remains $l_{0}{ }^{3}$. Thus, aerosol cloud interaction becomes

\footnotetext{
*For correspondence. (e-mail: prijithss@gmail.com)
}

the major source of uncertainty in estimation of anthropogenic climate forcing ${ }^{8-10}$. This uncertainty arises mainly because of the large heterogeneity in physical and chemical characteristics of aerosols, along with the variability in its spatial and temporal distribution ${ }^{11}$. Diversity in production mechanisms, including natural and anthropogenic processes, makes the aerosol characteristics highly heterogeneous ${ }^{12}$. Delineating natural and anthropogenic contribution in total aerosol loading is essential for the proper estimates of human impacts on the Earth's climate. This is highly challenging, especially over the regions which are in the vicinity of major sources of natural and anthropogenic aerosols. Indian subcontinent is one such region which experiences aerosol loading with contribution from both of these sources, with large variability in relative contributions depending on the regions and seasons ${ }^{13-15}$. While close proximity to oceanic and desert regions causes significant amount of natural aerosol loading, rapid growth in urbanization and industrialization lead to large amount of anthropogenic aerosol concentration over the Indian subcontinent. Though challenging, delineating anthropogenic and natural contributions in total aerosol loading is essential in estimating the radiative impacts of aerosols $\mathrm{s}^{16,17}$ and hence in policymaking, especially in view of air quality and climate change issues.

Different approaches are being used to delineate natural and anthropogenic contributions in aerosol loading, by making use of the differences in physical and chemical properties of different types of aerosols. Collected samples of aerosols are subjected to chemical analysis for the source apportionment ${ }^{18,19}$. Differences in spectral characteristics exhibited by different aerosols are being used by satellite remote sensing, for this purpose ${ }^{20,21}$. However, mixing up of natural and anthropogenic aerosols, with different physical and chemical characteristics, makes it highly challenging. Aerosol models, along with measured aerosol properties, are being used to estimate radiative impacts of natural and anthropogenic aerosols ${ }^{17,22}$. There are studies which made use of events such as national strikes, when vehicular and industrial activities are stopped, to examine the human impacts on aerosol loading over India ${ }^{23-25}$. These studies are based on such events extending only for few days. However, aerosols 
reside in the atmosphere for a period of few days. Due to the lockdown declared in India, to control spread of COVID-19 virus, most of the anthropogenic activities, including usage of vehicles and functioning of industries, have reduced for a long period. This has led to significant reduction in emission of various anthropogenic components, including aerosols, into the atmosphere. Changes in absorbing and composite aerosol loading over India during lockdown are examined in the preset study using multi-year, multi-satellite measurements of aerosol properties.

\section{Data and methodology}

In order to examine the changes in aerosol loading during lockdown, quality assured level 3 aerosol optical depth (AOD) at $550 \mathrm{~nm}$ from Moderate Resolution Imaging Spectroradiometer (MODIS) onboard Aqua ${ }^{26-28}$, along with level 3 data of AOD, absorption aerosol optical depth (AAOD) and single scattering albedo (SSA) at $500 \mathrm{~nm}$ from the Ozone Monitoring Instrument (OMI) onboard Aura satellite ${ }^{29}$ are used. Both Aqua and Aura make Earth observations in the afternoon hours, as part of the A-Train satellite constellation, where Aura lags Aqua by 15 minutes ${ }^{30}$. Uncertainty associated with AOD retrievals from MODIS over land is reported to be $0.05 \pm$ $0.15 \times$ AOD, in comparison with ground-based measurements ${ }^{28}$. Sub-pixel level cloud contamination is a major factor affecting the accuracy of aerosol retrieval from $\mathrm{OMI}^{29}$. However, AAOD from OMI is reported to be more reliable, as the uncertainties in extinction optical depth and SSA cancel out each other in the estimation of $\mathrm{AAOD}^{29,31}$. In order to avoid the errors due to extreme values, AOD and AAOD values greater than 2 are not considered for the analysis. These aerosol parameters during the first phase of lockdown (25 March to 14 April 2020) are compared with those during the same period in the previous years. The analysis is carried out by comparing mean of these aerosol parameters during the first phase of lockdown period, 25 March to 14 April 2020 (hereafter LD2020), with the same period in 2019 (hereafter RF2019) and also with the mean during the same period in past five years, 2015 to 2019 (hereafter RF2015-2019). In order to examine vertical distribution of aerosols and dust loading over India, L2 data of aerosol extinction coefficient profiles at $532 \mathrm{~nm}$ and cloud free L3 data of dust and polluted dust AOD from CALIOP are used in the study. CALIOP onboard Cloud Aerosol Lidar and Infrared Pathfinder Satellite Observations (CALIPSO) provide vertical profiles of aerosol parameters, along its sub-satellite track, using the lidar measurements at $532 \mathrm{~nm}$ and $1064 \mathrm{~nm}$ (ref. 32). Contribution of forest fires in aerosol loading over India during LD2020 is examined using collection 6 active fire data from Aqua-MODIS observations ${ }^{33}$. MODIS fire detection algorithm identifies fire pixels, of $1 \mathrm{~km} \times 1 \mathrm{~km}$ spatial resolution, which contains active fires.

\section{Results and discussion}

\section{Changes in columnar aerosol loading}

Changes in total columnar aerosol loading during the first phase of lockdown, compared to the same period in previous years, are examined and shown in Figure 1. Figure $1 a$ depicts difference in columnar AOD from MODIS observations during LD2020, compared to that during RF2019, whereas Figure $1 b$ shows the same using AOD measurements from OMI. Observations from both the satellites show similar spatial patterns of AOD changes over India. While regions of Indo Gangetic Plain (IGP) and southern peninsula show decrease in aerosol loading, regions of Centralwest and Northeast India show increase. MODIS observations show highest decrease in aerosol abundance over the eastern parts of IGP. However, aerosol loading shows large inter annual variability due to changes in several factors including source activities, long range transport and prevailing meteorological conditions. Hence, further analysis is carried out by comparing aerosol loading during the lockdown period to mean aerosol loading during the previous five years. Significance of the observed changes in AOD is examined by comparing them with corresponding inter annual variability. Figure $1 c$ and $d$ show changes in AOD during LD2020, compared to the mean AOD during RF20152019, from MODIS and OMI observations respectively. Black dots embedded in the figures show the regions,
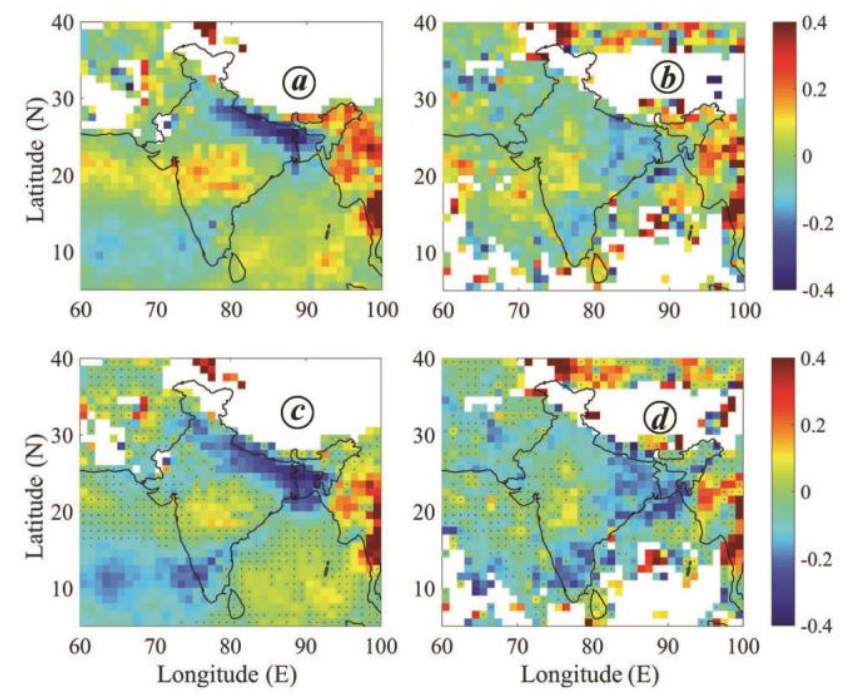

Figure 1. Difference in columnar AOD from (a) MODIS and (b) OMI during LD2020, compared to RF2019. (c) and (d) are the same as (a) and $(\boldsymbol{b})$, but show the difference in AOD between LD2020 and RF2015-2019. Black dots indicate the regions where observed changes are within the corresponding inter annual variability. 
where observed changes are within the inter annual variability. Inter annual variability in each pixel is estimated by computing the standard deviation of annual mean AOD values during 2015 to 2019. Differences in AOD seen over the remaining regions are considered significant, as the observed changes are greater than the inter annual variability. By considering only those pixels in which observed changes in aerosol loading are significant, MODIS (OMI) observations show a decrease in mean AOD by $-22.86 \pm 1.78 \%(-28.47 \pm 1.64 \%)$ over the Indian land mass during LD2020, in comparison with the previous five year mean (RF2015-2019). These changes are observed to be $-16.17 \pm 1.35 \%$ and $-22.4 \pm 1.36 \%$ from MODIS and OMI respectively, when all the pixels are considered. Differences between the estimated changes in AOD from both the satellites are mainly due to the differences in spatial coverage due to subpixel level cloud contamination with OMI $\mathrm{AOD}^{29}$, in addition to the differences in retrieval methodologies ${ }^{34}$.

Industrial and vehicular emissions are two major anthropogenic sources of absorbing aerosols, such as black carbon, into the atmosphere. Sudden cut off of such activities leads to reduction in anthropogenic absorbing aerosols in the atmosphere. Figure $2 a$ shows the decrease in AAOD during LD2020, in comparison with that during RF2015-2019. AAOD also shows similar spatial pattern of decrease as that of columnar AOD. Decrease in AAOD over Indian land regions is seen to be $-34.61 \pm 1.11 \%$ during LD2020, compared to that during RF2015-2019, while considering only those pixels in which the changes are significant, whereas it is $-26.2 \pm 1.17 \%$, when all the pixels are considered. AAOD also shows increase during LD2020 over some regions of Northeast and Westcentral India. Decrease in absorption aerosols due to the reduction in anthropogenic activities has increased the relative dominance of natural scattering aerosols over India, as seen in the difference in SSA depicted in Figure $2 b$. Figure $2 b$ shows the SSA increase during LD2020, compared to that during RF2015-2019. Increase in SSA is observed over most of the regions, including IGP, central India and southern peninsula. This shows the relative increase in scattering type aerosols over India during the lockdown period, compared to the same period in pre-

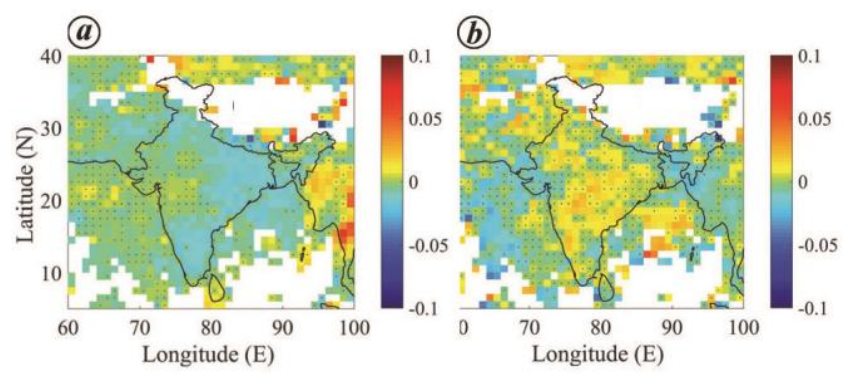

Figure 2. Change in (a) absorption aerosol optical depth (AAOD) and (b) single scattering albedo (SSA) at $500 \mathrm{~nm}$ from OMI during LD2020, compared to that during RF2015-2019. vious years. Percentage change of AOD (from MODID) and AAOD (from OMI), compared to those during RF2015-2019 is shown in Figure $3 a$ and $b$ respectively. Black dots in the figure show the pixels where the changes are within the inter annual variability.

Percentage changes in total and absorbing aerosols over different regions of Indian land mass during LD2020 are examined in detail. Supplementary Figure 1 shows the different regions considered for the analysis. Bar diagram shown in Figure $4 a$ depicts the percentage changes in total and absorbing aerosols over these regions during LD2020, in comparison with those during RF2015-2019. Figure $4 b$ is same as Figure $4 a$, but by considering only those pixels, in which the changes are greater than corresponding inter annual variability. Green and red bars in Figure 4 show percentage changes in AOD from MODIS and OMI respectively, whereas blue bars represent the changes in AAOD. While an increase in AOD of $5.16 \pm 2.44 \%(6.82 \pm 2.86 \%)$ is seen over $\mathrm{CW}$, reduction of $-38.05 \pm 1.06 \% \quad(-39.4 \pm 1.12 \%), \quad-23.02 \pm 2.63 \%$ $(-17.08 \pm 2.12 \%)$ and $-18.98 \pm 2.86 \%(-28.38 \pm 2.39 \%)$ is seen over IGP, NW and SP, from MODIS (OMI) observations. These values are seen to be $8.5 \pm 4.46 \%$ $(12.3 \pm 4.09 \%), \quad-38.52 \pm 0.97 \% \quad(-39.89 \pm 1.03 \%)$, $-32.13 \pm 2.02 \%(-25.85 \pm 3.36 \%)$ and $-24.75 \pm 3.48 \%$ $(-33.53 \pm 2.1 \%)$ over CW, IGP, NW and SP respectively, when only those pixels having changes greater than inter annual variability are considered. Reduction in absorbing aerosols is observed to be $-39.18 \pm 1.25(-40.19 \pm$ $1.06 \%)$ over IGP and $-33.1 \pm 2.03(-36.71 \pm 1.69 \%)$ over $\mathrm{SP}$, when all the pixels (only those with significant changes) are considered.

\section{Vertical distribution of aerosols}

Changes in columnar aerosol abundance are caused by the changes in both surface level and free tropospheric aerosol loading. While surface level aerosol concentration is significantly contributed by local production, free tropospheric aerosol loading has large contribution from long range transport. Changes in aerosol loading at different altitude levels are examined by comparing mean
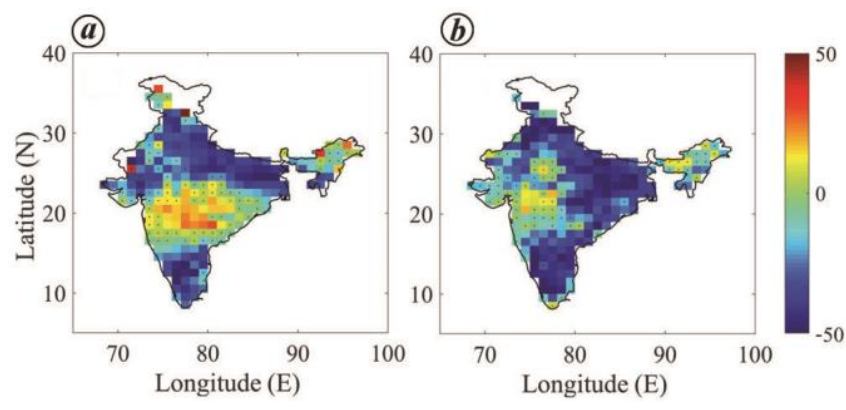

Figure 3. Percentage change in (a) AOD from MODIS and (b) AAOD from OMI, during LD2020, compared to those during RF20152020

CURRENT SCIENCE, VOL. 120, NO. 2, 25 JANUARY 2021 
aerosol extinction coefficient profiles over different regions of Indian land mass during LD2020, with the same during RF2015-2019. Blue curves in Figure 5 show vertical distribution of aerosols over NW, CW, CE, IGP, NE, SP and Indian landmass during RF2015-2019, whereas the red curves show the same during LD2020 and black curves show the difference in aerosol extinction coefficient during LD2020 in comparison with that during RF2015-2019. The analysis is carried out by using L2 aerosol extinction coefficient profiles from CALIOP observations in both day and night time. Values of $\mathrm{N}_{2015}$, $\mathrm{N}_{2016}, \mathrm{~N}_{2017}, \mathrm{~N}_{2018}, \mathrm{~N}_{2019}, \mathrm{~N}_{2020}$ in the figure show total number of profiles with valid measurements in 2015, 2016, 2017, 2018, 2019 and 2020 respectively over different regions. Mean values of aerosol extinction coefficients are computed at each altitude, only if the number of valid measurements available at that altitude is more than $5 \%$ of the total number of profiles within that region. Blue horizontal bars associated with the profiles during RF2015-2019 show the standard deviations representing the inter-annual variability during the period from 2015 to 2019. Positive (negative) values indicated by the black curves show increase (decrease) in aerosol loading during LD2020, compared to that during RF2015-2019. Significant difference (greater than the inter-annual variability) in aerosol concentration can be seen over several regions at higher altitudes. Fractional contribution of difference in aerosol loading at altitudes above $2 \mathrm{~km}$, in total columnar difference, is estimated to be $19 \%, 27 \%, 37 \%$, $25 \%, 39 \%$ and $26 \%$ over NW, CW, CE, IGP, SP and entire Indian landmass respectively. The analysis reveals that the changes in columnar aerosol loading, during LD2020, are considerably contributed by the changes in
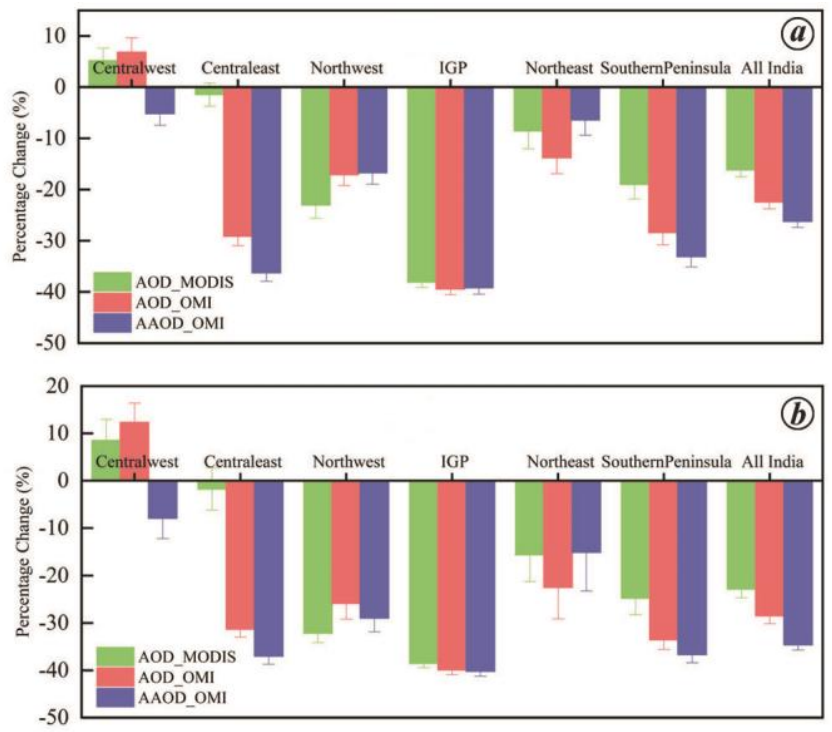

Figure 4. Percentage changes in AOD and AAOD over different regions of Indian land mass during LD2020, compared to those during RF2015-2020, by considering ( $\boldsymbol{a}$ ) all pixels and (b) only those pixels in which changes are greater than inter annual variability. elevated aerosols. Enhancement in aerosol concentration can be seen at altitudes around $\sim 3 \mathrm{~km}$ over $\mathrm{CW}$, where columnar AOD also shows increase as shown in Figure $1 c$ and $d$. Increase in elevated aerosol concentration can also be seen at altitudes around $5 \mathrm{~km}$ over CW, CE and NW. However, the results presented here on the vertical distribution of aerosols are subjected to the poor spatial coverage of CALIOP, as the lidar makes measurements only along its sub-satellite track with a footprint of $\sim 70 \mathrm{~m}$ diameter on Earth's surface.

In general, elevated aerosol over Indian region in premonsoon is largely contributed by transported mineral dust aerosols. In order to examine the contribution of dust aerosols in the observed changes in columnar aerosol loading, dust aerosol concentration in April 2020 is compared with that in the previous years, using L3 CALIPSO data from both day and night time observations. Figure 6 shows change in dust AOD and polluted dust AOD in April 2020, compared to mean of the same in April during the previous five years (2015 to 2019). Black dots in the figure indicate the changes which are within the
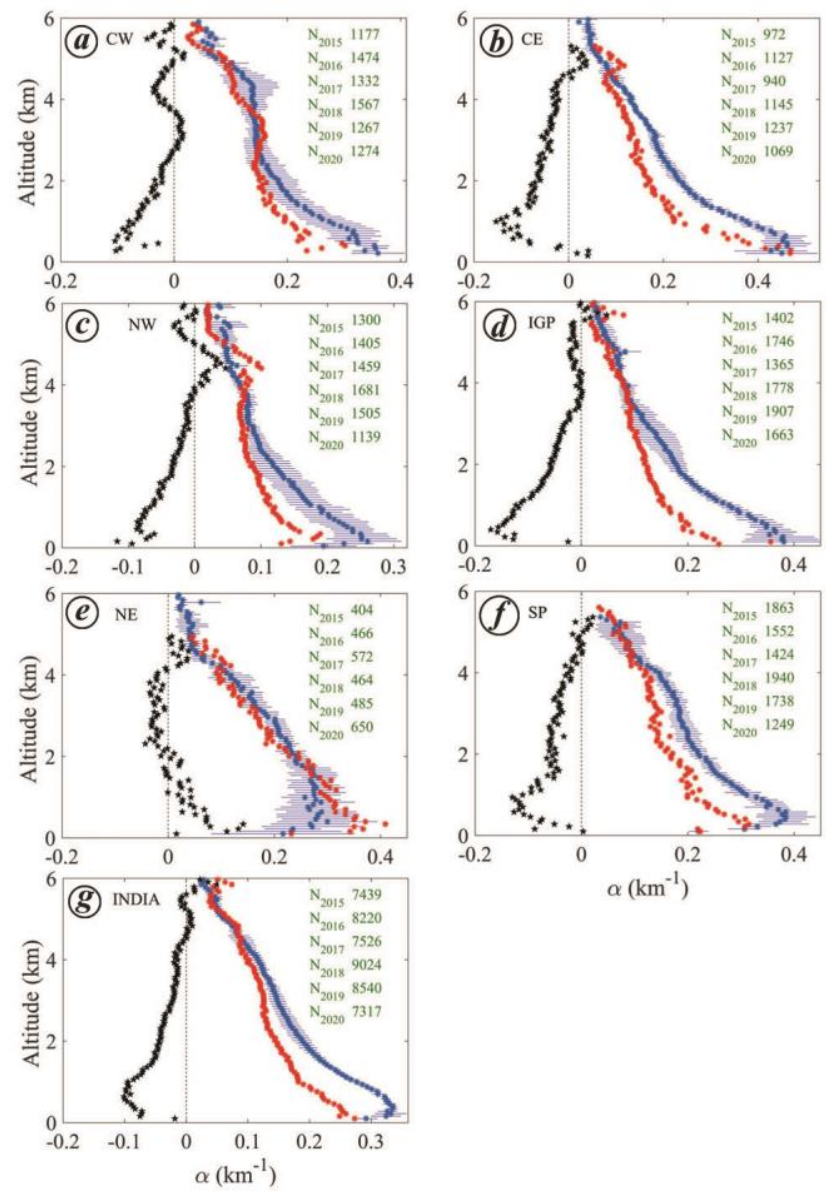

$\alpha\left(\mathrm{km}^{-1}\right)$

Figure 5. Mean vertical profiles of aerosol extinction coefficient $(\alpha)$ during LD2020 (red), RF2015-2020 (blue) and their difference (black) over (a) Centralwest, (b) Centraleast, (c) Northwest, (d) IGP, (e) Northeast, $(\boldsymbol{f})$ Southern Peninsula and $(g)$ Indian landmass. $N$ shows the total number of valid profiles in each year. 
inter-annual variability during the period from 2015 to 2019. Considerable decrease in dust aerosols is seen over large regions of Indian landmass, especially over the regions of IGP. This shows that the decrease in mineral dust transport, compared to previous years, contributed largely to the overall decrease in columnar aerosol loading. However, increase in concentrations of polluted dust aerosols is seen over west central regions of India, where enhancement in total and absorbing aerosols is seen. Thus the analysis reveals that the changes in columnar aerosol loading observed over India during the lockdown period are significantly contributed by the changes in dust aerosol loading, in addition to the decrease in anthropogenic emissions.

In addition to dust loading, presence of black carbon (BC) aerosols is reported at higher altitudes over Indian region, based on high altitude balloon experiments ${ }^{35,36}$. This elevated $\mathrm{BC}$ layers are proposed to be due to the emissions from aircrafts ${ }^{35,36}$. This BC aerosols get uplifted even up to lower stratospheric heights, where they can reside for longer period ${ }^{36}$. Restrictions implemented for air travel, during the lockdown, reduced aircraft emitted $\mathrm{BC}$ aerosols at higher altitudes. This also contributed to the observed reduction in both elevated and columnar aerosol loading over India during the lockdown phase.
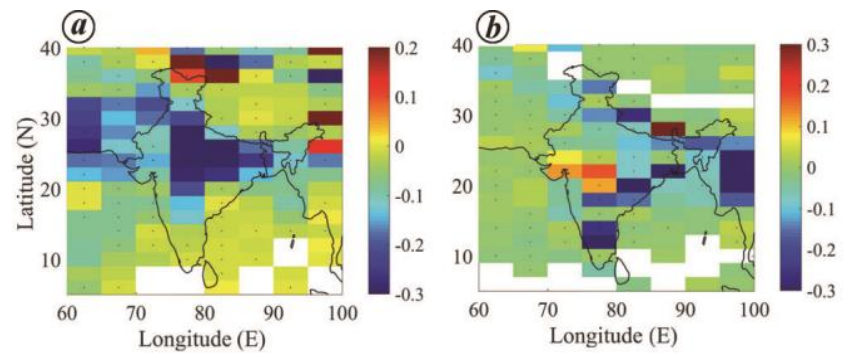

Figure 6. Difference in $(\boldsymbol{a})$ dust AOD and $(\boldsymbol{b})$ polluted dust AOD in April 2020, compared to the mean in April during 2015 to 2019, using L3 CALIPSO data. Positive (negative) values indicate regions of AOD increase (decrease) in April 2020. Black dots indicate the regions where observed changes are within the inter annual variability.

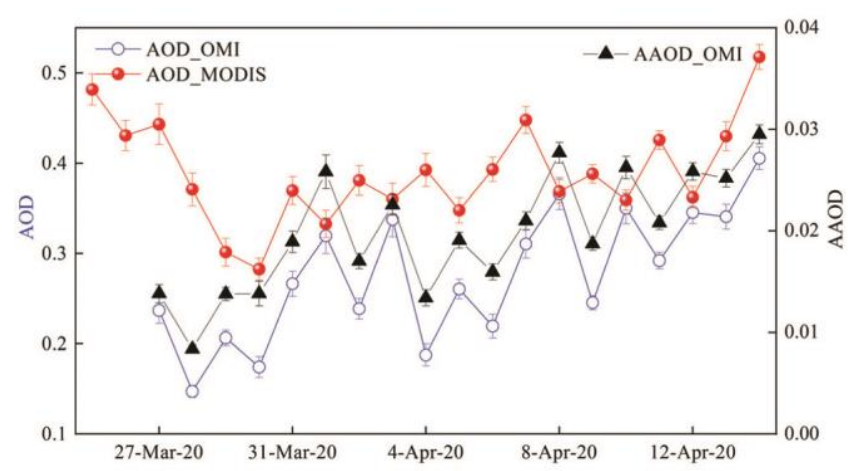

Figure 7. Time series of daily mean MODIS AOD, OMI AOD and OMI AAOD, over Indian landmass during the period from 25 March to 14 April 2020.

\section{Influence of dust aerosol transport over India in pre-monsoon}

In contrast to the expected decrease in aerosol loading due to the sudden cut off of anthropogenic sources, an increase in AOD and AAOD is seen during the lockdown as shown in Figure 7. The figure depicts day to day changes in total and absorbing aerosol abundance over India during the first phase of lockdown period, from 25 March to 14 April 2020. While red circles show daily mean AOD values over the entire Indian land mass from MODIS observations, blue open circles and black triangles show daily mean AOD and AAOD respectively from OMI measurements. Associated vertical bars in each curve represent corresponding standard errors. Daily mean values of these parameters are considered, only if more than $30 \%$ of the pixels covering the entire country have valid measurements. As mentioned earlier, difference between MODIS AOD and OMI AOD is mainly due to the difference in spatial coverage due to subpixel level cloud contamination with the latter ${ }^{29}$. It can be seen from Figure 7 that mean AOD and AAOD started decreasing for initial few days of the lockdown, from 25 to 30 March 2020. After that aerosol abundance over India is observed to be increasing, even in the absence of anthropogenic industrial and vehicular emissions.

Prevailing surface level winds over these regions are northwesterly or westerly during pre-monsoon. This brings large amount of dust aerosols, from the arid continental regions at west, in addition to the supply of sea salt aerosols from the Arabian Sea. Long range transport of dust aerosols over to India and Arabian Sea during premonsoon and summer monsoon is reported by several earlier studies ${ }^{37-41}$. Though dust aerosols scatter visible light, increase in hematite content can make it more absorbing and appear brownish ${ }^{42,43}$. Mixing up of dust with absorbing aerosols such as black carbon also makes them more absorbing in nature ${ }^{14,43}$. Figure 8 shows change in mean dust AOD in April 2020, compared that in the previous month, March 2020, using L3 CALIOP data. While Figure $8 a$ shows the difference using day time CALIOP observations, Figure $8 b$ shows the same using mean of

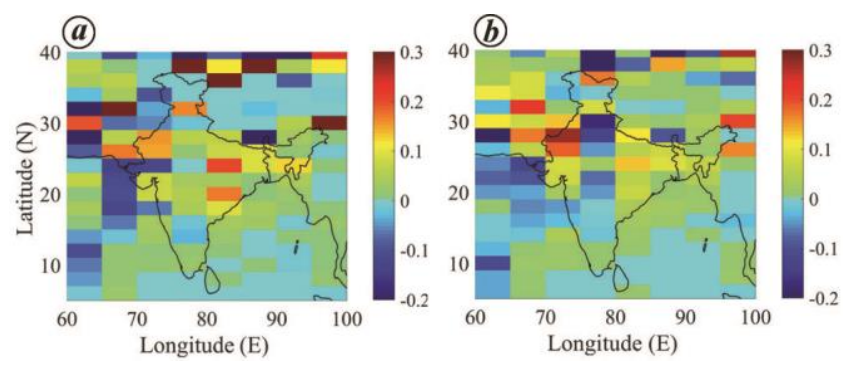

Figure 8. Difference in dust AOD in April 2020, compared to that in March 2020, from L3 CALIPSO data of $(\boldsymbol{a})$ day time and $(\boldsymbol{b})$ day and night mean. Positive values indicate increase of dust AOD in April. 
day and night time measurements. Positive (negative) values in the figure indicate regions of increase (decrease) in dust aerosol loading in April 2020. Considerable increase in dust aerosol loading can be seen over several regions of Indian land mass, in April 2020, compared to the previous month. The analysis shows that the gradual increase in aerosol loading observed during the lockdown period, in the absence of major anthropogenic emission sources, is mainly contributed by the long range transport of dust aerosols. This leads to large fraction of dust aerosols over India, especially at higher altitudes, during pre-monsoon.

\section{Satellite detected active fires over India in pre-monsoon}

Forest fires are significant over the Indian region during pre-monsoon months ${ }^{44}$. Biomass burning due to forest fires contributes considerably to aerosol loading. Satellite detection of fire activities is widely used for identification of biomass burning ${ }^{45,46}$. Figure 9 shows the locations of active fire with high confidence, during LD2020, from Aqua-MODIS observations. High confidence fire locations are identified by considering only those pixels with confidence values ranging from 80 to 100 (ref. 47). Large number of active fires is seen over the regions of Northeast India. It shows that the absorbing and total aerosol loading over these regions are largely contributed by the biomass burning due to forest fires. Regions of central, west and south India also show considerable number of active fires. Thus the mineral dust transported from the western regions get mixed with these biomass burning aerosols and become more polluted dust aerosols as seen from the CALIPSO observations shown in Figure $6 b$.

The analysis carried out here shows that the reduction in total columnar aerosol loading during the first phase of the lockdown in India is only $20 \%$ and that in absorbing

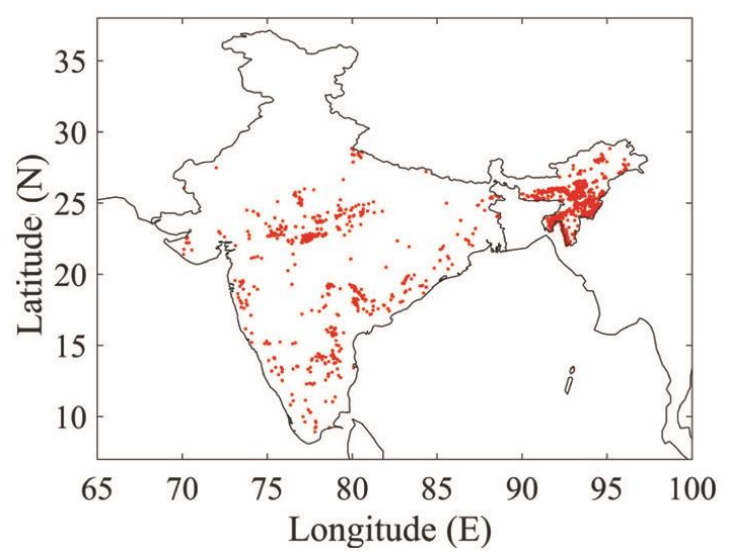

Figure 9. Locations of active fire with high confidence (confidence value from 80 to 100), over India during LD2020, from Aqua-MODIS observations. aerosols is $26 \%$, even in the absence of major anthropogenic sources. This reduction in columnar aerosol abundance is significantly contributed by the changes in aerosol loading at higher altitudes. In general, elevated aerosol loading over India during pre-monsoon is largely contributed by transported dust aerosols. The analysis also shows the contribution of decrease in dust aerosols in the overall reduction of columnar aerosol loading. Though there is a reduction, in comparison with previous years, aerosol loading is observed to be increasing during the lockdown phase. This increase is observed to be due to the strengthening of dust aerosol transport from the arid continental regions at west. Biomass burning due to forest fire also contributes to pre-monsoon aerosol loading over India, especially over the Northeastern regions. Though anthropogenic aerosol sources are absent during lockdown, reduction in aerosol loading observed over India is significantly contributed by the decrease in natural aerosols. Thus the results presented in the study show the dominance of natural aerosols over Indian region in pre-monsoon.

\section{Conclusions}

Proper estimation of relative contribution of anthropogenic aerosols in total aerosol loading is essential for the assessment of human impacts on the Earth's climate. Due to the lockdown declared in India, to contain the spread of COVID-19 virus, anthropogenic emissions from industrial activities and vehicular transport were cut for a long period under the lockdown phase. During the first phase of lockdown, $26 \%$ reduction in absorbing and $20 \%$ reduction in composite aerosols are seen over India, compared to the same period in previous years. However, considerable fraction of this columnar difference is contributed by the aerosol changes at higher altitudes. While reduction in columnar aerosol abundance is observed over the regions including IGP and southern peninsula, enhancement is seen over some regions of Westcentral and Northeast India. Reduction in columnar aerosol loading is significantly contributed by the decrease in dust aerosols, in addition to the reduction in anthropogenic aerosol emissions. Increase in absorbing and total aerosol loading over Centralwest India is observed to be due to the increase in polluted dust aerosols, whereas the aerosol loading over Northeast India has large contribution from biomass burning due to forest fire. Though there is an overall reduction, compared to previous years, amount of absorbing and composite aerosols is observed to be increasing during the lockdown period, after a decrease for initial few days, even in the absence of major anthropogenic aerosol source activities. This increase is observed to be due to the strengthening of dust aerosol transport from the arid continental regions at west. This long range transport of dust aerosols leads to large fraction of natural 
aerosols over India during pre-monsoon. The results presented in this study show the dominance of natural aerosols over India during pre-monsoon and its large interannual and spatial variability. Proper quantification of these variations in natural aerosols is vital to delineate the relative contributions of natural and anthropogenic aerosols and their proper incorporation in model simulations to estimate their impacts on climate.

Disclaimer: The observations/statements made in this article are the sole viewpoints of the authors and do not anyway represent those of the organization to which they belong.

1. Charlson, R. J., Schwartz, S. E., Hales, J. M., Cess, R. D., Coakley Jr, J. A., Hansen, J. E. and Hofmann, D. J., Climate forcing by anthropogenic aerosols. Science, 1992, 255, 423-430.

2. Russell, P. B., Hobbs, P. V. and Stowe, L. L., Aerosol properties and radiative effects in the United States east coast haze plume: An overview of the Tropospheric Aerosol Radiative Forcing Observational Experiment (TARFOX). J. Geophys. Res., 1999, 104(D2), 2213-2222.

3. IPCC (Intergovernmental Panel for Climate Change), Climate Change 2013: The Physical Science Basis, Cambridge University Press, Cambridge, 2014.

4. McCormick, R. and Ludwig, J., Climate modification by atmospheric aerosols. Science, 1967, 156(3780), 1358-1359.

5. Charlson, R. and Pilat, M., Climate: The influence of aerosols. J. Appl. Meteorol., 1969, 8, 1001-1002.

6. Coakley Jr, J. A., Cess, R. D. and Yurevich, F. B., The effect of tropospheric aerosols on the Earth's radiation budget: A parameterization for climate models. J. Atmos. Sci., 1983, 40, 116-138.

7. Twomey, S., The influence of pollution on the shortwave albedo of clouds. J. Atmos. Sci., 1977, 34, 1149-1152.

8. IPCC (Intergovernmental Panel for Climate Change), Climate Change 2007: The Physical Science Basis, Cambridge, United Kingdom, 2007.

9. Carslaw, K. S. et al., Large contribution of natural aerosols to uncertainty in indirect forcing. Nature, 2013, 503(7474), 67-71.

10. Rosenfeld, D., Wood, R., Donner, L. J. and Sherwood, S. C., Aerosol cloud-mediated radiative forcing: highly uncertain and opposite effects from shallow and deep clouds. In Climate Science for Serving Society, Springer, Dordrecht, 2013, pp. 105-149.

11. Penner, J. E. et al., Quantifying and minimizing uncertainty of climate forcing by anthropogenic aerosols. Bull. Am. Meteorol. Soc., 1994, 75(3), 375-400.

12. Prospero, J. M. et al., The atmospheric aerosol system: an overview. Rev. Geophys. Space Phys., 1983, 21(7), 1607-1629.

13. Moorthy, K. K., Babu, S. S., Manoj, M. R. and Satheesh, S. K., Build up of aerosols over the Indian region. Geophys. Res. Lett., 2013, 50, 1011-1014.

14. Prijith, S. S., Babu, S. S., Lakshmi, N. B., Satheesh, S. K. and Moorthy, K. K., Meridional gradients in aerosol vertical distribution over Indian mainland: Observations and model simulations. Atmos. Environ., 2016, 125, 338-345.

15. Prijith, S. S., Rao, P. V. N., Mohan, M., Sai, M. V. R. S. and Ramana, M. V., Trends of absorption, scattering and total aerosol optical depths over India and surrounding oceanic regions from satellite observations: Role of local production, transport and atmospheric dynamics. Environ. Sci. Poll. Res., 2018, 25(18), 18147-18160.

16. Satheesh, S. K. and Moorthy, K. K., Radiative effects of natural aerosols: A review. Atmos. Environ., 2005, 39(11), 2089-2110.
17. Ramachandran, S., Srivastava, R., Kedia, S. and Rajesh, T. A., Contribution of natural and anthropogenic aerosols to optical properties and radiative effects over an urban location. Environ. Res. Lett., 2012, 7(3), 034028.

18. Nair, P. R., Parameswaran, K., Sunilkumar, S. V., Abraham, A. and Jacob, S., Chemical composition of atmospheric aerosols over the Indian Ocean: impact of continental advection. Adv. Space Res., 2004, 34(4), 828-832.

19. Nair, V. S., Satheesh, S. K., Moorthy, K. K., Babu, S. S., Nair, P. R. and George, S. K., Surprising observation of large anthropogenic aerosol fraction over the 'near-pristine' southern Bay of Bengal: Climate implications. J. Geophys. Res., 2010, 115(D21), $1-10$.

20. Omar, A. H. et al., The CALIPSO automated aerosol classification and lidar ratio selection algorithm. J. Atmos. Oceanic Tech., 2009, 26(10), 1994-2014.

21. Mao, Q., Huang, C., Chen, Q., Zhang, H. and Yuan, Y., Satellitebased identification of aerosol particle species using a 2D-space aerosol classification model. Atmos. Environ., 2019, 219, 117057.

22. Allen, R. J. and Sherwood, S. C., The impact of natural versus anthropogenic aerosols on atmospheric circulation in the Community Atmosphere Model. Clim. Dyn., 2011, 36(9-10), 1959-1978.

23. Latha, K. M., Badarinath, K. V. S. and Moorthy, K. K., Impact of diesel vehicular emissions on ambient black carbon concentration at an urban location in India. Curr. Sci., 2004, 86(3), 451-453.

24. Kompalli, S. K., Moorthy, K. K. and Babu, S. S., Rapid response of atmospheric BC to anthropogenic sources: observational evidence. Atmos. Sci. Let., 2014, 15(3), 166-171.

25. Mahalakshmi, D. V., Sujatha, P., Naidu, C. V. and Chowdary, V. M., Response of vehicular emissions to air pollution and radiation A case study during public strike in Hyderabad, India. Sustaine. Environ. Res., 2015, 25(4), 227-234.

26. Kaufman, Y. J. et al., Passive remote sensing of tropospheric aerosol and atmospheric correction for the aerosol effect. J. Geophys. Res., 1997, 102(D14), 16815-16830.

27. Ichoku, C., Kaufman, Y. J., Remer, L. A. and Levy, R., Global aerosol remote sensing from MODIS. Adv. Space. Res., 2004, 34(4), 820-827.

28. Remer, L. A. et al., The MODIS aerosol algorithm, products, and validation. J. Atmos. Sci., 2005, 62(4), 947-973.

29. Torres, O. et al., Aerosols and surface UV products from Ozone Monitoring Instrument observations: an overview. J. Geophys. Res., 2007, 112(D24), 1-14.

30. Stephens, G. L. et al., The CloudSat mission and the A-Train: A new dimension of space-based observations of clouds and precipitation. Bull. Am. Meteorol. Soc., 2002, 83(12), 1771-1790.

31. Livingston, J. M. et al., Comparison of aerosol optical depths from the Ozone Monitoring Instrument (OMI) on Aura with results from airborne sunphotometry, other space and ground measurements during MILAGRO/INTEX-B. Atmos. Chem. Phys., 2009, 9(18), 6743-6765.

32. Winker, D. M., Hunt, W. H. and McGill, M. J., Initial performance assessment of CALIOP. Geophys. Res. Lett., 2007, 34, L19803.

33. Giglio, L., Schroeder, W. and Justice, C. O., The collection 6 MODIS active fire detection algorithm and fire products. Remote Sens. Environ., 2016, 178, 31-41.

34. Li, J., Carlson, B. E. and Lacis, A. A., Application of spectral analysis techniques in the intercomparison of aerosol data: Part III. Using combined PCA to compare spatiotemporal variability of MODIS, MISR, and OMI aerosol optical depth. J. Geophys. Res., 2014, 119(7), 4017-4042.

35. Babu, S. S. et al., Free tropospheric black carbon aerosol measurements using high altitude balloon: Do BC layers build 'their own homes' up in the atmosphere? Geophys. Res. Lett., 2011, 38(8), L08803(1-6). 
36. Govardhan, G., Satheesh, S. K., Nanjundiah, R., Moorthy, K. K., and Babu, S. S., Possible climatic implications of high-altitude black carbon emissions. Atmos. Chem. Phys., 2017, 17(15), 9623.

37. Aloysius, M., Sijikumar, S., Prijith, S. S., Mohan, M. and Parameswaran, K., Role of dynamics in the advection of aerosols over the Arabian Sea along the west coast of peninsular India during pre-monsoon season: A case study based on satellite data and regional climate model. J. Earth Syst. Sci., 2011, 120(2), 269-279.

38. Prijith, S. S., Rajeev, K., Thampi, B. V., Nair, S. K. and Mohan, M., Multi-year observations of the spatial and vertical distribution of aerosols and the genesis of abnormal variations in aerosol loading over the Arabian Sea during Asian Summer Monsoon Season. J. Atmos. Sol. Terr. Phys., 2013, 105, 142-151.

39. Prijith, S. S., Rao, P. V. N. and Mohan, M., Genesis of elevated aerosol loading over the India region. SPIE Asia Pac. Rem. Sens., 2016, 988208, 1-11.

40. Babu, S. S. et al., Trends in aerosol optical depth over Indian region: Potential causes and impact indicators. J. Geophys. Res., 2013, 118(20), 11-794.

41. Vinoj, V., Rasch, P. J., Wang, H., Yoon, J. H., Ma, P. L., Landu, K. and Singh, B., Short-term modulation of Indian summer monsoon rainfall by West Asian dust. Nature Geosci., 2014, 7(4), 308-13.

42. Deepshikha, S., Satheesh, S. K. and Srinivasan, J., Regional distribution of absorbing efficiency of dust aerosols over India and adjacent continents inferred using satellite remote sensing. Geophys. Res. Lett., 2005, 32(3), L03811(1-4).
43. Moorthy, K. K., Babu, S. S., Satheesh, S. K., Srinivasan, J. and Dutt, C. B. S., Dust absorption over the 'Great Indian Desert' inferred using ground-based and satellite remote sensing. J. Geophys. Res., 2007, 112(D9), 1-10.

44. Sahu, L. K., Sheel, V., Pandey, K., Yadav, R., Saxena, P. and Gunthe, S., Regional biomass burning trends in India: Analysis of satellite fire data. J. Earth Syst. Sci., 2015, 124(7), 1377-1387.

45. Ellicott, E., Vermote, E., Giglio, L. and Roberts, G., Estimating biomass consumed from fire using MODIS FRE. Geophys. Res. Lett., 2009, 36, L13401.

46. Freeborn, P. H., Wooster, M. J., Roy, D. P. and Cochrane, M. A., Quantification of MODIS fire radiative power (FRP) measurement uncertainty for use in satellite-based active fire characterization and biomass burning estimation. Geophys. Res. Lett., 2014, 41, 1988-1994.

47. Giglio, L., Schroeder, W., Hall, J. V. and Justice, C. O., Modis collection 6 active fire product user's guide revision A, Department of Geographical Sciences, University of Maryland, 2015.

ACKNOWLEDGEMENTS. We acknowledge NASA for providing MODIS aerosol data through https://ladsweb.modaps.eosdis.nasa.gov, MODIS active fire data through https://firms.modaps.eosdis.nasa.gov, OMI aerosol data through https://disc.gsfc.nasa.gov, CALIPSO L2 data through https://subset.larc.nasa.gov and CALIPSO L3 data through https://opendap.larc.nasa.gov.

doi: $10.18520 / \mathrm{cs} / \mathrm{v} 120 / \mathrm{i} 2 / 352-359$ 